\title{
Offenders' perceptions of the UK prison smoking ban
}

\begin{tabular}{|r|l|}
\hline Journal: & International Journal of Prisoner Health \\
\hline Manuscript ID & IJPH-06-2018-0034.R2 \\
\hline Manuscript Type: & Research Paper \\
\hline Keywords: & smoking, offenders, Prison, thematic analysis, focus group, smoke-free \\
\hline \multicolumn{2}{|}{} \\
\hline
\end{tabular}

SCHOLARONE ${ }^{\text {m }}$

Manuscripts 


\title{
Offenders' perceptions of the UK prison smoking ban
}

\author{
Stephanie Dugdale ${ }^{1}$, Heather Semper ${ }^{2}$, Rachel Povey ${ }^{2}$, Sarah Elison-Davies ${ }^{1}$, Glyn Davies, \\ Jonathan Ward ${ }^{1}$ \\ ${ }^{1}$ Breaking Free Group, Manchester \\ ${ }^{2}$ Staffordshire University, Stoke-on-Trent \\ *corresponding author \\ Tel: +441618344647 \\ Email address: sdugdale@breakingfreegroup.com \\ Address: Breaking Free Group,_BASE, Manchester Science Park, Greenheys Lane, \\ Manchester, M15 6LR
}

\section{Acknowledgements}

We would like to acknowledge and thank the prison staff and governors for providing access to participants and for supporting this research. 
Abstract

Purpose

Despite overall reductions in levels of smoking in the UK, rates of offender smoking remain high. In 2016 it was announced that prisons in Wales and England would gradually introduce a smoking ban. The purpose of this research was to explore offenders' perceptions around the upcoming smoking ban.

Design

A total of eight focus groups were conducted in four prisons across the North of England. Both smoking and non-smoking offenders participated in the focus groups, and thematic analysis was used to explore the findings.

\section{Findings}

Themes generated from the data were 'freedom and rights', 'the prison environment', and 'guiding support'. Participants discussed how the smoking ban was viewed as a punishment and restricted their freedom, with perceptions as to why the ban was being implemented centring around others trying to control them. Participants expressed concerns around the financial implications of the smoking ban on already stretched prison resources. Participants also recommended improving the nicotine replacement therapy on offer; and increasing the range of leisure activities within the prison to prepare for the smoking ban.

\section{Value}

Overall, it was apparent that participants' awareness of the smoking ban was generally poor. It is recommended that offenders need to be made more aware of the smoking cessation support they will receive and given the opportunity to ask questions about the smoking ban. Increasing offenders' awareness of the ban may reduce stress associated with a perceived lack of choice around their smoking behaviours.

\section{Keywords}

smoking; offenders; prison; thematic analysis; focus groups; smoke-free 


\section{Background}

Over one billion people smoke worldwide, with tobacco killing approximately six million people globally each year as a combined result of direct and second-hand smoking (World Health Organization, 2015, 2016). Most deaths related to smoking can be attributed to cancer, respiratory disease and cardiovascular disease (Jha, 2009). Due to the life-threatening consequences associated with smoking and second-hand smoking, in 2007, the UK Government introduced legislation to ban smoking in enclosed public places and made it illegal for under 18s to buy tobacco (Rutter et al., 2012). In 2007, prisons in England also banned smoking in indoor areas, excluding cells occupied by smokers aged 18 years old or over (HMP Service, 2007).

Smoking in prisons is a major public health concern, with the prevalence of smoking in offenders estimated at $80 \%$, approximately four times that of the prevalence in the general UK population (Cropsey et al., 2010). Evidence suggests that the prison environment may exacerbate these outcomes, with just under $15 \%$ of offenders reporting starting smoking, and approximately $50 \%$ of smokers reporting increasing usage whilst being inside prison (Cropsey et al., 2008). Reasons behind smoking in prisons include stress management, boredom and use of smoking as a social aid (Butler et al., 2007; Richmond et al., 2009).

Recently, countries including Canada (Collier, 2013) and New Zealand (Beaglehole \& Bonita, 2017), and some US states (Cropsey \& Kristeller, 2003) have adopted a smoking ban within their prisons. This has led to mixed reactions across these sites. For example, in Quebec, Canada, the 2008 smoking ban was reversed following riots in prisons (McNabola \& Gill, 2009). Despite later bans there, evidence from 2011 suggests that approximately 93\% of offenders still used tobacco with few facing consequences for doing so (Collier, 2013). Cropsey and Kristeller (2005) also found that $76 \%$ of offenders continued to smoke in US prisons after the ban. Similarly, evidence suggests that smoking bans alone have little effect of maintenance of smoking cessation upon release (de Andrade \& Kinner, 2017; Valera et al., 2016). On the other hand, evidence has also demonstrated the health 
benefits associated with these bans. Studies in prisons in the US and New Zealand, following the implementation of a prison smoking ban, have found a reduction on indicators of smoke particles and nicotine concentration of between 50\% to $80 \%$ (Hammond \& Emmons, 2005; Proescholdbell et al., 2008; Thornley et al., 2012). After time in a tobacco-free US prison, compared to health when first incarcerated, offenders improved on symptoms of asthma, depression and stress (Clarke et al., 2015). In one recent study conducted in English prisons, airborne particulate matter, a measure of second-hand smoke, was measured in smoking areas and compared to that of non-smoking areas (Jayes et al., 2016). In smoking areas, levels of particulate matter were between 2 and 9 times higher than that of the World Health Organisation's recommended daily average, whereas the non-smoking areas in the prisons were below this recommendation. This highlights the long-term deleterious effects that these smoking areas can have on a person's health and shows the distinct advantages of the ban in reducing smoke particles within the environment.

Amidst disagreements as to whether prisons are considered public places, in 2016, it was announced that prisons across England and Wales would introduce a phased smoking ban (Selous, 2015). This smoking ban is inclusive of areas inside and outside of the prison. Prisons in Scotland are also implementing a similar smoking ban, with prisons to be smoke-free by the end of 2018 (Scottish Prison Service, 2017). When this research was conducted, in Spring 2017, all prisons in Wales but only a few prisons in England had become smoke-free, with plans for all prisons to be smoke-free in 2018 (National Offender Management Service, 2017). Despite the benefits associated with introducing a smoking ban, there may be potential difficulties met when implementing and maintaining this.

A recent study has explored the views of offenders and prison staff from one prison in England about the upcoming prison smoking ban. Woodall and Tattersfield (2017) explored the perceived impact of the ban on the organisation and safety of the prison, in relation to anticipated increases in offender violence resulting from the ban. These anticipated increases in violence may be 
linked to the high rate of smoking within UK prisons and the removal of the use of smoking, which is perceived as a coping aid (Butler et al., 2007; Cropsey et al., 2010; Richmond et al., 2009). Offenders considered the ban as an additional punishment alongside their sentence and felt that the ban imposed restrictions to their human right to choose whether or not they can smoke. This was reported to increase feelings of frustration within offenders, leading to the belief that this would result in an increase in violence.

The research by Woodall and Tattersfield (2017) is unique in that there is an overall scarcity of literature investigating offenders' qualitative perceptions of smoking bans in custodial settings, despite the ban directly affecting them and their behaviour. This includes those countries where a smoking ban has already been implemented within prisons. One of the limitations to the study by Woodall and Tattersfield (2017) is that focus groups were only conducted within one prison in England of low-security (category C). Arguably therefore, this data may not represent the perceptions of other types of prisons or offenders. The focus groups also contained a mix of both smoking and non-smoking offenders. Whilst it is beneficial to explore the impact on all offenders alongside a change in the prison, this mixed group may have been less likely to share their feelings compared to a homogenous sample (Schutt, 2012).

The aim of this research is to build upon the existing literature regarding offenders' perceptions of the upcoming smoking ban in English and Welsh prisons, and thus provide recommendations towards best practice and the safe implementation of this and future smoking bans. This is key, as offender and prison staff safety should be paramount during the implementation of a prison smoking ban. As the ban will have implications for all offenders within prison, this research seeks to elicit the views of both offenders who are smokers and non-smokers respectively, across several prison estates, of categories B and C, in the North of England. Category B prison offenders do not need to be placed under high security, but escape should be very difficult. Category $\mathrm{C}$ prison offenders cannot be trusted in open conditions, yet are considered unlikely to 
escape. Within these prisons, the smoking ban is due to come into effect within several months. A secondary aim of the article is to collect data assessing offenders' perceptions of the barriers and facilitators to smoking cessation alongside perceptions of the prison smoking ban, expanding upon the work of Woodall and Tattersfield (2017).

\section{Design}

This study used qualitative methodology to explore offenders' perceptions of the smoking ban in prisons in England. Data were collected using focus groups and analysed using inductive thematic analysis.

Participants

Male offenders were recruited across four prisons from the North of England. For accessibility purposes, prisons were selected based on where the authors had an existing professional working relationship. Of these, three prisons were classified as category B prisons and one as a category $\mathrm{C}$ prison. Male prisons were chosen as recruitment sites as these were considered to contain a more representative sample of the prison population, as the average gender divide in UK prisons is $95 \%$ male (Allen \& Watson, 2017). Purposive sampling was used to recruit offenders who wished to participate in the focus groups. Prison staff within each prison site helped to identify and recruit potential participants who met the inclusion criteria for participation in the focus groups. This was important for ensuring the safety of participants within the group, as prison staff were aware of any offenders who should be kept separate from one another. Information sheets were given to these potential participants, by prison staff, as means of advertising the study. Participants were recruited if they met the following inclusion criteria:

- Adult male offenders currently serving their sentence in a UK prison;

- Participants identified as being either a current smoker or a current non-smoker. A smoker 
is defined as someone who has had a cigarette within the past month, as after a month, cravings and withdrawal symptoms subside substantially (Fiore \& Lewis, 1994).

- Participants had to be healthy (physically and mentally) enough to be able to attend and contribute to the focus group.

A total of eight focus groups were conducted between the four prisons; four focus groups were conducted with smokers from each respective prison, and four with non-smokers from each respective prison. The groups contained between four to seven participants. Between the groups, 26 participants were classified as smokers and 21 as non-smokers. See Table 1 for participant demographic information. The focus groups were conducted in Spring 2017, with the smoking ban gradually being brought into these establishments from Autumn 2017-Winter 2017/2018.

\section{Ethical considerations}

Approval for this research was granted by the National Offender Management Service on $18^{\text {th }}$ October 2016 (NRC ref: 2016-298). Further approvals were granted by Staffordshire University's ethics committee on $1^{\text {st }}$ March 2017. The British Psychological Society's Code of Ethics and Conduct was adhered to throughout this research (British Psychological Society, 2009).

Data collection

Separate focus groups of smoking and non-smoking offenders were conducted by SD. Focus groups were supervised by a member of prison staff to ensure participant and researcher safety. The focus groups were conducted using a semi-structured interview schedule to guide the sessions and to probe for further detail around offenders' perceptions of the upcoming smoking ban in prisons. Questions included probes around perceived triggers for smoking; perceptions of how the ban will 
impact themselves, other offenders, or prison staff; the current availability of smoking cessation support; and suggestions around best practice for the implementation of the ban.

The focus groups were recorded using a Dictaphone and lasted for an average of 46 minutes. Participants were given a debrief form at the end of the interview, which stated the aims of the research, and reminded participants that they could withdraw their data within 30 days following the interview.

Data analysis

Braun and Clarke's (2006) inductive model of thematic analysis was used to investigate the qualitative focus group data. This method of analysis was chosen as it best suited the aims of this research; to explore and understand what the general perceptions of offenders are towards the smoking ban.

Following Braun and Clarke's (2006) method, transcripts were read and re-read to increase familiarity with the data and NVivo software (NVivo 10, 2012) was used to support the analysis of the data. All transcripts were inductively coded line-by-line, summarising data using the software to generate 'nodes'. Nodes (codes) were then searched for patterns of similarity, and merged using the software, to create themes. Themes were reviewed against the transcripts to ensure that the themes accurately described the data. These themes were then defined to reflect the content of these findings. SD conducted this initial analysis. Code generation and theme selection were then reviewed by two researchers (SD and HS) to ensure the reliability of the findings (Pope et al., 2000). After examination and discussion of the themes, there was complete agreement over the findings. 


\section{Results}

Offenders' perceptions of the upcoming smoking ban in prisons were separated into three distinct themes and are reported below using selected quotes to illustrate the findings. These themes are 'freedom and rights', 'the prison environment', and 'guiding support'. Initially, the views of both smoking and non-smoking offenders were collected and analysed separately to investigate whether there were any discrepancies between these groups, however on analysis, the perceptions of both groups largely mapped on to each other and are hence reported together. Pseudonyms are used in place of participant names to protect identity.

\section{Freedom and rights}

This theme reports offenders' fears that the smoking ban would further reduce the freedom that they have over their behaviour. Offenders discuss the ways in which their freedom to smoke may be reinstated, and the anticipated consequences of the ban including increased violence and riots.

i) Control

Concerns centred around others controlling their behaviour. Participants not only viewed smoking as a personal right, but that the ability to smoke or not to smoke was a matter of personal choice. Participants felt that this choice, and freedom to make decisions about their own health, were being removed from them:

\footnotetext{
"It would be an unjust thing, and I don't think that freedom of choice should be taken out of your hands or, d'you know what I mean? I don't think they should be making that choice. I think it should be down to the individual." (Simon, smoker, focus group 2)
} 
Linked to these views around the removal of power and control is the perception of a smoking ban as a punishment. Some offenders reported that this smoking ban was akin to adding further restrictions to their prison sentence instead of focusing on rehabilitation:

"Surely you've got a right as well in prison. It's not punishment, prison, it's meant to be rehabilitation, so why take things away from us that we're allowed out there?" (John, nonsmoker, focus group 7)

\section{ii) Making sense of the ban}

To better explain their thoughts towards the smoking ban, participants would often compare smoking to other health behaviours, to explain why smoking was different, and therefore should not be banned:

"I understand with alcohol, 'cause it's a substance that makes us act in different ways, and what not, but with smoking, smoking's smoking, isn't it?" (John, non-smoker, focus group 7)

In this example, smoking is not seen as being as harmful as alcohol consumption, as it is does not impact people's behaviour or conduct. Additionally, the smoking ban was compared with treatments for other addictive behaviours, to highlight concerns around the implementation of the smoking ban and their reduced ability to choose how and when they quit:

"Obviously with an addiction, they detox you eventually, but with the smoking we've just got a date." (Peter, smoker, focus group 8)

iii) Rebellion

Ultimately, these smoking restrictions were thought to increase anger amongst offenders, 
leading to concerns over increased violence and bullying:

"I think the big one of your concerns is people getting beat up because people are angry, violent, violence is going to be a massive." (Matthew, non-smoker, focus group 5)

To regain this control and freedom over their behaviour, participants openly discussed rebelling against the ban:

"I think that's when people rebel against it a bit more. I think that's the point, people don't like being told you can't do something: you're not allowed to smoke! Oh, I'm gonna do it!" (Andrew, non-smoker, focus group 1)

There was a distinction between the reported methods that participants said they could use to rebel. Some discussed intentions to stop smoking before the ban was implemented, thus quitting on their own terms rather than those imposed upon them:

\footnotetext{
"That's why he's quit, because he had that much taken off him all his life by the prison system, just give it up now, so they can't take it off him in sixteen weeks." (William, nonsmoker, focus group 7)
}

However, others mentioned plans to rebel through obtaining tobacco, so they could continue to smoke after the ban is implemented:

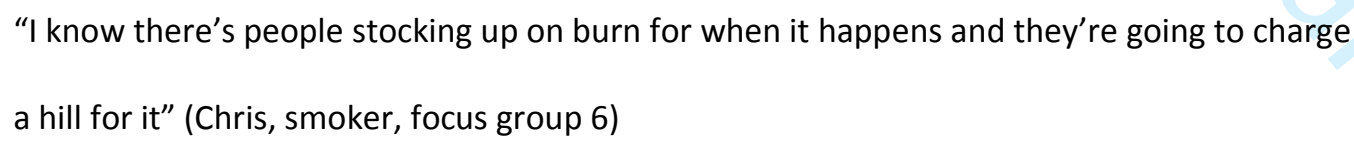


In this example, the participant predicts that prices for tobacco products within the prison are going to increase once the smoking ban is implemented. However, this method of regaining control by 'stockpiling' or 'smuggling' is fraught with its own difficulties, and many mentioned the additional harm that this could lead to:

“They're just gonna try and extort more money out of prisoners, and it's just gonna lead to a lot more violence and mental health issues." (Peter, smoker, focus group 8)

Offenders mention that having to purchase tobacco whilst in prison, via smuggling it in after the ban is implemented, could lead to debts, as extortionate prices may be charged for this product. However, it was envisioned that these debts may not only affect offenders themselves, but also members of their family, who may end up having to settle any debts the offender cannot pay:

“It's just gonna make us get into debt, which in turn will apply pressure to families. I mean, I've seen people's families getting threatened and violence." (Dave, smoker, focus group 2)

Moreover, it was discussed how the risks and costs associated with smuggling tobacco could lead to the popularity of other unregulated and illegal products, such as novel psychoactive substances:

\footnotetext{
"I can get spice or I can get smack in prison a lot easier than I can get hold of a pouch of backy, so I'll just resort to that, so it's one of those, isn't it?" (Gary, non-smoker, focus group
} 3) 


\section{The prison environment}

Offenders discussed potential difficulties with the implementation of the ban in line with the structure of the prison environment and estate across prisons in England and Wales. This encapsulates individual issues such as sentence types and mixed cells, alongside service-wide issues, such as staffing and healthcare.

i) Cost

Offenders reported their experiences of the effects of financial cuts to the prison service, and discussed how the ban may warrant additional resources which may no longer be covered due to these changes:

"It's gonna cost more policing the non-smoking ban than it is actually smoking in your cell, 'cause officers' time, nickings, visits, everything." (Peter, smoker, focus group 8)

Offenders discussed how cuts to staffing and resources may affect how well the smoking ban is enforced. It was surmised that implementing the smoking ban would take up more officers' time than the value attached to the crime would be worth, which may lead to a poor enforcement of the ban:

"I don't think they can financially afford to stop smokers, because they haven't got the people to support them, and they haven't got the money to pay for them, they're struggling to get more staff, more smoke patches and things like that." (Gary, non-smoker, focus group 4)

\section{ii) Smoking cessation support}

Participants discussed the current smoking cessation support services operating in prisons, 
and perceived that the services did not have the capacity to support those who wanted to stop smoking, even before the ban was announced:

"I've been in six months, and I still haven't got my medication, so the healthcare's not good enough to cope for the rise of people wanting support for no smoking." (Simon, smoker, focus group 2)

iii) Other inmates

Some participants mentioned the impact of sharing cells and wings with others, with fears that tensions between offenders currently in prison and offenders who are newly introduced into prison will increase as tobacco is removed:

\begin{abstract}
"All you have to do is say the wrong thing to someone, like, try and have a joke around people on our wing, say if he's not had a cigarette that day, the first thing he's gonna do is lamp you." (Andrew, non-smoker, focus group 1)
\end{abstract}

"You've got people coming in straight snapping off, every smoking lad getting thrown on the wing every couple of days, some guys...stressing out to death, and all that." (Jamie, smoker, focus group 8)

Differences between various offender groups were also considered, alongside thoughts as to how the smoking ban would affect them. The smoking ban was thought to have little impact on offenders with a life sentence, as their sentence would not change as a result of breaking prison rules by ignoring the ban: 
"They're doing life, they've got nothing to lose, a lot of them are doing multiple life sentences." (Liam, smoker, focus group 8)

Also discussed was the impact on those who are remanded in custody, and therefore have not actually been charged with any offence, as yet, but may have to lose their 'right' to smoke whilst in prison:

\author{
"If you're unconvicted and you're innocent, that entitlement to smoke ultimately taken \\ away." (Rob, smoker, focus group 8)
}

\title{
Guiding support
}

Lastly, offenders discussed that they needed support to help them to succeed in their quit attempts in preparation for the smoking ban. They identified improvements to current pharmacological support and suggested behavioural support may also be useful.

\section{i) Pharmacological support}

Offenders considered changes to the types of nicotine replacement therapy (NRT) available, as they did not perceive their current NRT as being as effective as that which could be purchased outside of prison:

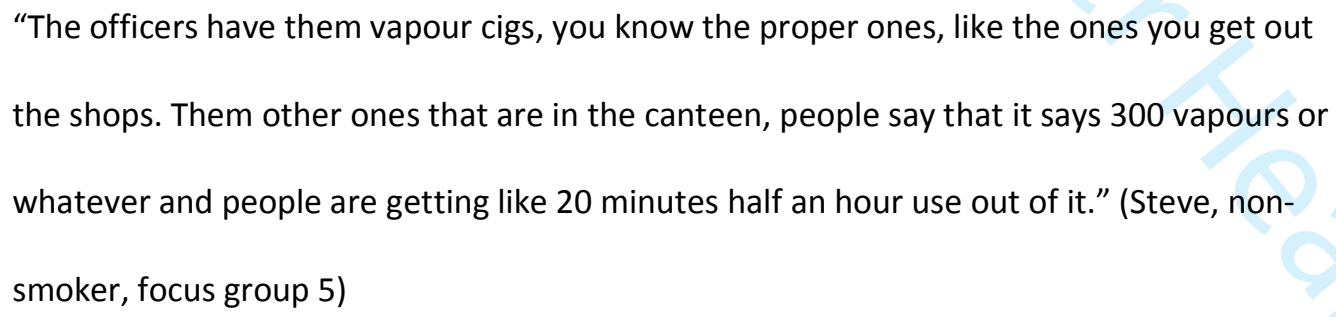


Offenders also suggested lowering the cost of NRT to make this more affordable to all offenders, which might encourage more to stop smoking:

“Making it freely available as well, not just your average one who's getting cash sent in. But there's people in here [...] they can't even buy the NRT off the canteen." (Tom, non-smoker, focus group 7)

"On the outside a lot of these products cost more than the actual tobacco does. So, some people who are leaving prison addicted to nicotine replacement." (Dave, smoker, focus group 2)

As seen in the latter example, some offenders reported potential difficulties with NRT, including addiction to nicotine. Alternative support methods were therefore also discussed within groups.

\section{ii) Alternative support}

As well as suggested improvements to the pharmacological support available, offenders also discussed the value of replacement activities in helping to stop smoking by reducing 'boredom':

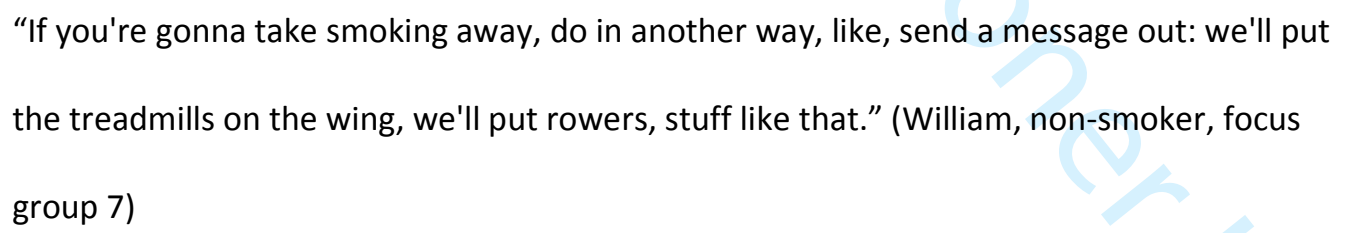


Although offenders were informed about the smoking ban, only offenders from one prison seemed to know the date that this ban would be implemented. Offenders who felt that they had not been properly informed of this date discussed the poor materials designed to raise awareness about the ban, and thought that this would impact negatively on the support sought in preparation for this:

\author{
"It should be on the hard smokers' doors and saying, 'Look this is happening soon, do you \\ want to start getting on the patches now so it's not so hard for you when you're coming off?' \\ It shouldn't just be like a little sign like that that someone might not read." (Phil, non- \\ smoker, focus group 5)
}

A further common suggestion proposed by offenders, in juxtaposition to a complete smoking ban, is to enforce well-defined smoking and non-smoking areas within the prison:

\begin{abstract}
"If you wanna smoke they should have a smoking wing, where you can smoke, and have the officers who do smoke working on that wing, so then if they are actually smoking they're not bothered are they?" (Trevor, smoker, focus group 8)
\end{abstract}

\title{
Discussion
}

This study has reported on the perceptions of smoking and non-smoking offenders regarding the upcoming smoking ban in prisons in England. The findings contribute to the limited available literature on the prison smoking ban from this viewpoint, including in other countries where similar bans have been implemented. This study aimed to expand upon the initial findings of Woodall and Tattersfield (2017) by gathering data across several prisons across the North of England, and additionally exploring barriers and facilitators to smoking cessation in conjunction with the smoking ban. 
Offenders discussed how the proposed smoking ban removed their right to choose whether they wanted to smoke, and whether they wanted to quit. However, this expands beyond simple choice, and encapsulates the perceived removal of their 'God-given' or human rights (Butler et al, 2007). Many offenders did not understand why the smoking ban was being implemented, especially as they did not think it was as harmful as other restricted items, such as alcohol. Interestingly, offenders perceived alcohol as harmful as it impacted people's conduct, unlike smoking. However, the removal of cigarettes and the act of quitting smoking was suggested to cause an increase in violence, which would imply that smoking does affect behaviour. Interestingly, health harms associated with both smoking and alcohol appear of secondary importance, whereas offenders' perceptions of their rights regarding acceptable behaviour is of primary concern.

Ethical considerations seem to underlie the belief that offenders perceive the smoking ban to be an additional punishment, on top of their sentence, for a behaviour which is 'acceptable' outside of prison. These findings support those of Woodall and Tattersfield (2017) by highlighting the concerns of offenders towards the ban and the discussion of the ban as a punishment, further reflecting offenders' perceived loss of choice around their behaviour alongside the smoking ban. This perhaps indicates that information about the ban and smoking cessation support need to be publicised more prominently in the lead up to the ban being imposed.

The theme of 'freedom and rights' depicts a potential power struggle between offenders and those enforcing the ban, which may impact upon the working conditions of prison staff also, due to reports of increased violence. Crewe (2009) discusses how offenders' power is limited within the prison environment and how offenders will adapt their behaviour accordingly to retain their identity and associated values. From the findings reported here, offenders suggested ways of adapting to the smoking ban. This included ways to continue to smoke through stockpiling tobacco and smuggling this into the prison. Attempts to re-gain control were also evident in suggestions for smoking and non-smoking areas within prisons. This would re-enable them with the choice of continuing to smoke if they wanted. However, there are already current restrictions on smoking within prisons, 
being that smoking should be confined to offenders' cells (HMP Service, 2007). Unfortunately, there are reports that this legislation is not well enforced within prisons (Woodall \& Tattersfield, 2017), again linking back to difficulties experienced within the prison environment and reflecting the consequences of reductions to prison staffing levels.

Rebelling against the ban may be a method by which to react to, and cope with, the potential stress associated with the smoking ban. Evidence suggests that stress can be appraised as a challenge, loss or threat (Jerusalem \& Schwarzer, 2014). Given that offenders identified the smoking ban as stressful, this stress could be appraised as a challenge, which offenders discuss ways to overcome through rebelling. On the other hand, a loss of control of smoking behaviours and associated stress appraised as a threat is also apparent within the findings. Offenders discussed concerns over increased violence and frustration resulting from the ban. There were also reports of potential tension between offenders sharing cells, especially if offenders who have only just had to stop smoking are brought into the prison. This situation is potentially problematic, as offenders perceived smoking as a means to reduce stress (Butler et al., 2007; Cropsey et al., 2010; Richmond et al., 2009). Although it should be acknowledged that fears over increased violence might not necessarily materialise into reality, potential stress caused by these fears does need highlighting. Further ethical concerns are therefore emphasised, and it is imperative that additional support is available alongside the prison smoking ban to help offenders find alternative ways to manage their stress.

Offenders discussed the option of substitute behavioural activities to support them with becoming smoke-free and to reduce the stress and boredom of not smoking (Richmond et al., 2009). By introducing more exercise equipment and options for additional television channels, offenders stated that these would help replace smoking by reducing the boredom which triggers this smoking behaviour. Also, as prisons are often associated with increased sedentary behaviour of offenders (De Viggiani, 2007), providing more exercise equipment could help offenders to become more physically active, and improve their health on top of the health benefits gained from stopping smoking (Ussher, 
2012). However, this would require additional funding in an already financially stretched prison estate (Edgar, 2014).

Offenders also stipulate important environmental structures that could affect the implementation of the smoking ban. They state that recent reductions to staff and services, due to financial cuts (Edgar, 2014), have seemed to affect smoking cessation support (Eadie et al., 2012; Public Health England, 2015). Difficulties with the smoking cessation services within prisons in England, such as long waiting lists for treatment, have also been reported in a previous study by Condon et al. (2008). This evidence would suggest that the smoking cessation support available in prisons may fall short of demand (Condon et al., 2008), which needs to be addressed in the lead up to the smoking ban. Offenders also mentioned perceived difficulties and cost associated with the current smoking cessation services, and suggested improvements to the NRT that was on offer. Conversely, one participant also cited experiences of others leaving prison addicted to NRT, which raises an important question as to whether there is any additional smoking cessation support that may be of benefit here. Research suggests that pharmacological support may be most effective in reducing smoking when used in tandem with behavioural support (Stead et al., 2016; West \& Stapleton, 2008).

Based on the findings of this study, it would appear that support, such as NRT, can be expensive on an individual level and difficult to implement on a larger scale (Condon et al., 2008). One way to overcome potential difficulties with smoking cessation support within prisons may lie with computer-assisted interventions. These offer high treatment fidelity and cost-effectiveness, as the intervention can be accessed by multiple users at once (Carroll \& Rounsaville, 2010; Olmstead et al., 2010). Evidence has already demonstrated the successful implementation of computer assisted therapy within prisons, including Breaking Free Health and Justice, the first online substance use recovery programme for offenders in the UK (Elison et al., 2016). The data from this study has been used to inform the development of an online smoking cessation intervention for offenders: Breaking Free from Smoking (Dugdale et al., 2018). 
Limitations

There are several limitations to this study that need acknowledging when considering the findings. Firstly, a member of prison staff had to supervise the focus groups alongside the lead investigator (SD). This was to ensure safety for the researcher and for the participants if a security incident were to arise. However, the presence of prison staff may have biased some of the findings, and influenced conscious decisions on what to discuss, as offenders were told that any information that was illegal or against prison rules would be reported. Therefore, offenders may have been more likely to give socially desirable answers (Stewart \& Shamdasani, 2015). This was also evident when offenders discussed illegal activities, such as smuggling, as answers were mostly around the potential illegal activities of others in the prison, rather than suggesting that they would partake in this. Furthermore, the focus group itself may have been affected by the social context, including the social status of offenders within the prison and relational backgrounds between participants, which may influence levels of engagement and participation within the groups (Farnsworth \& Boon, 2010).

Finally, this research only conducted focus group interviews with offenders from category B and $\mathrm{C}$ prisons. It would be of interest to explore the opinions of offenders throughout the prison system, including those who are remanded in custody and those with a life sentence, as discussed by participants. Future research may also wish to investigate the perceptions of female offenders towards the smoking ban, and whether there are any differences in reports between genders. Conducting similar focus groups during prisons' transition to become smoke-free, and after, may also provide further insight into perceptions of the smoking ban as it is occurring.

\section{Conclusion}

This research contributes to the limited available literature on the prison smoking ban from the viewpoint of offenders, and expands upon the initial findings of Woodall and Tattersfield (2017) by exploring barriers and facilitators to smoking cessation which may impact upon the efficacy of the 
smoking ban. Despite plans and progress towards all prisons in England becoming smoke-free, offenders' awareness about the ban and the implication of this appeared generally poor across the prisons. Offenders discussed that the posters about the smoking ban were not clear enough, and opportunities to support offenders leading up to the ban were not actioned. Reasons behind this may lie with the current difficulties experienced across the prison estate, including cuts to funding for staffing and healthcare, which may act as barriers towards the implementation of the ban. From these findings, the authors propose the following recommendations to policy and practice around the implementation of a prison smoking ban:

1) Offenders should be fully aware of smoking ban implementation plans and of the smoking cessation support that they can expect to receive alongside the ban. This includes an opportunity to ask questions about why and how the ban is being implemented. Clarifying this may reduce stress surrounding the lack of control that offenders experience in relation to the proposed smoking ban.

2) Funding needs to be allocated to smoking cessation support and healthcare services alongside the ban to manage the increase in numbers accessing these services.

3) Alternative forms of smoking cessation support, aside from pharmacological support, need to be investigated and considered, such as behavioural support.

\section{References}

Allen, G. and Watson, C. (2017), “UK prison population statistics”, briefing paper, House of Commons Library, London, UK.

Beaglehole, R. and Bonita, R. (2017), "Eliminating the scourge of tobacco for a fairer and healthier world: New Zealand leads the way", The Lancet Public Health, Vol. 22 No. 1, pp. e12-e13.

Braun, V. and Clarke, V. (2006), "Using thematic analysis in psychology". Qualitative Research in Psychology, Vol. 3 No. 2, pp 77-101.

British Psychological Society (2009), "Code of ethics and conduct", guidelines, Author, Leicester, UK. 
Butler, T., Richmond, R., Belcher, J., Wilhelm, K. and Wodak, A. (2007), "Should smoking be banned in prisons?", Tobacco Control, Vol. 16 No. 5, pp. 291-293.

Carroll, K. M. and Rounsaville, B. J. (2010), “Computer-assisted therapy in psychiatry: Be brave-it's a new world", Current Psychiatry Reports, Vol. 12 No. 5, pp. 426-432.

Clarke, J. G., Martin, S. A., Martin, R. A., Stein, L. A. R., van den Berg, J. J., Parker, D. R., ... and Bock, B. C. (2015), “Changes in smoking-related symptoms during enforced abstinence of incarceration", Journal of Health Care for the Poor and Underserved, Vol. 26 No. 1, pp. 106-118.

Collier, R. (2013), "Prison smoking bans: Clearing the air", Canadian Medical Association Journal, Vol. 185 No. 10, pp. E474.

Condon, L., Hek, G. and Harris, F. (2008), “Choosing health in prison: Prisoners' views on making healthy choices in English prisons", Health Education Journal, Vol. 67 No. 3, pp. 155-166.

Crewe, B. (2009), The prisoner society: Power, adaptation and social life in an English prison, Oxford University Press, Oxford, UK.

Cropsey, K. L., Jones-Whaley, S., Jackson, D. O. and Hale, G. J. (2010), "Smoking characteristics of community corrections clients", Nicotine \& Tobacco Research, Vol. 12 No. 1, pp. 53-58.

Cropsey, K. L., and Kristeller, J. L. (2003), “Motivational factors related to quitting smoking among prisoners during a smoking ban", Addictive Behaviors, Vol. 28, pp. 1081 - 1093.

Cropsey, K L., and Kristeller, J. L. (2005), "The effects of a prison smoking ban on smoking behavior and withdrawal symptoms", Addictive Behaviors Vol. 30 No. 3, pp. 589-594.

Cropsey, K. L., Linker, J. A. and Waite, D. E. (2008), “An analysis of racial and sex differences for smoking among adolescents in a juvenile correctional center", Drug and Alcohol Dependence, Vol. 92 No.1-3, pp. 156-163.

de Andrade, D. and Kinner, S. A. (2017), "Systematic review of health and behavioural outcomes of smoking cessation interventions in prisons", Tobacco Control, Vol. 26 No. 5, pp. 495-501.

de Viggiani, N. (2007), "Unhealthy prisons: exploring structural determinants of prison health", Sociology of Health \& IIIness, Vol. 29 No. 1, pp. 115-135. 
Dugdale, S., Ward, J., Elison-Davies, S., Davies, G., and Brown, E. (2018), "Breaking Free from Smoking: A Novel Digital Smoking Cessation Intervention for Offenders in UK Prisons", early online view, Journal of Smoking Cessation.

Eadie, D., MacAskill, S., McKell, J. and Baybutt, M. (2012), "Barriers and facilitators to a criminal justice tobacco control coordinator: An innovative approach to supporting smoking cessation among offenders", Addiction, Vol. 107 No. S2, pp. 26-38.

Edgar, K. (2014), "Making prisons safe”, Prison Reform Trust, London, UK.

Elison, S., Weston, S., Davies, G., Dugdale, S. and Ward, J. (2016), “Findings from mixed-methods feasibility and effectiveness evaluations of the "Breaking Free Online" treatment and recovery programme for substance misuse in prisons", Drugs: Education, Prevention and Policy, Vol. 23 No. 2, pp. $176-185$.

Farnsworth, J. and Boon, B. (2010), "Analysing group dynamics within the focus group”, Qualitative Research, Vol. 10 No. 5, pp. 605-662.

Fiore, M. C. and Lewis, S. (1994), "Smoking cessation", in Love, R. R. (Ed.), Manual of clinical psychology, Springer-Verlag Berlin Heidelberg, Geneva, CH, pp. 101-113.

Hammond, S. K. and Emmons, K. M. (2005), "Inmate exposure to secondhand smoke in correctional facilities and the impact of smoking restrictions", Journal of Exposure Science and Environmental Epidemiology, Vol. 15 No. 3, pp. 205-211.

HMP Service. (2007), "Smoke free legislation: Prison service application”, Author, London, UK. Jayes, L. R., Ratschen, E., Murray, R. L., Dymond-White, S. and Britton, J. (2016), "Second-hand smoke in four English prisons: An air quality monitoring study", BMC Public Health, Vol. 16 No. 119.

Jerusalem, M. and Schwarzer, R. (2014), "Processes", in Schwarzer, R. (Ed.), Self-efficacy: Thought control of action, Routledge, New York, NY, pp. 195-214.

Jha, P. (2009), "Avoidable global cancer deaths and total deaths from smoking" Nature Reviews Cancer, Vol. 9 No. 9, pp. 655-664. 
McNabola, A. and Gill, L. W. (2009), "The control of environmental tobacco smoke: A policy review", International journal of Environmental Research and Public Health, Vol. 6 No. 2, pp. 741-758.

National Offender Management Service. (2017), “Annual report and accounts 2016-2017", Author, London, UK.

NVivo 10. (2012), "NVivo qualitative data analysis software", QSR International Pty, Limited.

Olmstead, T. A., Ostrow, C. D. and Carroll, K. M. (2010), “Cost-effectiveness of computer-assisted training in cognitive-behavioral therapy as an adjunct to standard care for addiction", Drug and Alcohol Dependence, Vol. 110 No. 3, pp. 200-207.

Pope, C., Ziebland, S. and Mays, N. (2000), "Qualitative research in health care: Analysing qualitative data", BMJ: British Medical Journal, Vol 320 No. 7227, pp. 114-116.

Proescholdbell, S. K., Foley, K. L., Johnson, J. and Malek, S. H. (2008), "Indoor air quality in prisons before and after implementation of a smoking ban law", Tobacco Control, Vol 17 No. 2, pp. $123-$ 127.

Public Health England (2015), "Reducing smoking in prisons: Management of tobacco use and nicotine withdrawal", Author, London, UK.

Richmond, R., Butler, T., Wilhelm, K., Wodak, A., Cunningham, M. and Anderson, I. (2009), "Tobacco in prisons: A focus group study", Tobacco Control, Vol. 18 No. 3, pp. 176-182.

Rutter, J., Sims, S. and Marshall, E. (2012), “The 'S' factors", Institute for Government, London, UK, available at: https://www.instituteforgovernment.org.uk/sites/default/files/smoking in public places.pdf

Schutt, R. K. (2012), Investigating the social world: The process and practice of research, Sage, Thousand Oaks, CA.

Scottish Prison Service. (2017), "Creating a smoke free prison environment. A summary of responses to the public consultation exercise", Author, Edinburgh, UK.

Selous, P. (2015, September 29). "Smoking in prisons", letter to Robert Neill MP, Chairman of the 
Justice Select Committee regarding smoking in prisons, available at:

https://www.gov.uk/government/speeches/smoking-in-prisons

Stead, L. F., Koilpillai, P., Fanshawe, T. R. and Lancaster, T. (2016), “Combined pharmacotherapy and behavioural interventions for smoking cessation", Cochrane Library: Cochrane Database of Systematic Reviews, Vol. 3 No. CD008286.

Stewart, D. W. and Shamdasani, P. N. (2015), Focus groups: Theory and practice, Sage, Thousand Oaks, CA.

Thornley, S., Dirks, K. N., Edwards, R., Woodward, A. and Marshall, R. (2012), "Indoor air pollution levels were halved as a result of a national tobacco ban in a New Zealand prison", Nicotine and Tobacco Research, Vol. 15 No. 2, pp. 343-347.

Ussher, M., Taylor, A. H. and Faulkner, G. (2012), "Exercise for smoking cessation”, Mental Health and Physical Activity, Vol. 5 No. 1, pp. 99-100.

Valera, P., Bachman, L. and Rucker, A. J. (2016), "A qualitative study of smoking behaviors among newly released justice-involved men and women in New York City", Health \& Social Work, Vol. 41 No. 2, pp. 121-128.

West, R. and Stapleton, J. (2008), "Clinical and public health significance of treatments to aid smoking cessation", European Respiratory Review, Vol. 17 No. 110, pp. 199-204.

Woodall, J. and Tattersfield, A. (2017), “Perspectives on implementing smoke-free prison policies in England and Wales", early online view, Health Promotion International.

World Health Organization (2015), “Global Health Observatory (GHO) data: Prevalence of tobacco smoking", available at: http://www.who.int/gho/tobacco/use/en/

World Health Organization (2016), "Tobacco", factsheet, available at: http://www.who.int/mediacentre/factsheets/fs339/en/ 
Table 1. Demographic characteristics of participants

\begin{tabular}{|c|c|c|}
\hline Demographics & Smoking participants & Non-smoking participants \\
\hline \multicolumn{3}{|l|}{ Age (years) } \\
\hline $18-25$ & 1 & 4 \\
\hline $26-35$ & 13 & 10 \\
\hline $36-45$ & 7 & 4 \\
\hline $46-55$ & 5 & 2 \\
\hline $56-65$ & - & - \\
\hline $66+$ & - & 1 \\
\hline \multicolumn{3}{|l|}{ Marital status } \\
\hline Single & 18 & 14 \\
\hline Married & - & 2 \\
\hline Divorced & 2 & 3 \\
\hline Living with partner & 6 & 2 \\
\hline \multicolumn{3}{|l|}{ Highest Education level } \\
\hline Primary school & 4 & 1 \\
\hline Secondary school & 12 & 8 \\
\hline Further education & 3 & 7 \\
\hline Higher education & 2 & 4 \\
\hline No formal education & 5 & 1 \\
\hline \multicolumn{3}{|l|}{ Ethnicity } \\
\hline White British & 26 & 18 \\
\hline Pakistani & - & 1 \\
\hline Caribbean & - & 1 \\
\hline Mixed White and Asian & - & 1 \\
\hline Total & 26 & 21 \\
\hline
\end{tabular}

